Surgical Journal," affords a remarkable instance. In the case quoted from the Medical Communications, it is stated that two ounces of fluid existed in the ventricles; but it is extremely improbable that so large an amount should have accumulated in little more than three days, without giving rise to symptoms of compression. The simple presence of fluid in the ventricle cannot be regarded as a morbid state, Dr. Sims having shown that two, four, and even six ounces, may be found in persons dying of diseases in no way connected with the brain, and in whom no cerebral symptoms were present during life. In the former case it will be observed that the heart was not examined; and in the last, the statement that it was found healthy, when viewed in connection with the imperfect knowledge of its pathology at that period, is not altogether to be relied upon.

It may be doubted whether atrophy of the heart was present in the last two cases quoted by Mr. Mayo, that gentleman not having had an opportunity of verifying his opinion by dissection. A trophy of the heart is described by writers on the diseases of that organ as of rare occurrence, except as an attendant on chronic diseases of debility ; and of the few cases on record in which it has been found, and the patients were under observation during life, the symptoms were alone referable to the disease which led to the fatal event-a remark which applies to two cases under my own observation, in which the heart was remarkably small; a condition in these cases, probably congenital, being combined with a similar state of the brain. We possess, therefore, no accurate knowledge of the phenomena to which atrophy of the heart would give rise; and Laennec expresses his opinion that it cannot in any case be regarded as a disease; adding, however, that "several hypochondriacs, who were liable to faintings from very slight causes, gave, under the stethoscope, signs of a very small heart."

The only case I have found recorded, in which an examination of the body took place after the pulse had observed a very slow rate, and in which the condition of the heart is stated, is that of Mr. Worthington's patient, who lived two years and a half. and in whom the heart was found very much softened. On the contrary, in the case of aneurism of the heart, to which I have before referred, the substance of that organ, so far from being softened, was unusually firm; the left ventricle was also hypertrophied, and its cavity much larger than usual. There existed in this case, probably, some regurgitation through the aortic orifice, and the symptoms during life were chiefly those of valvular obstruction on the right side, from the pressure of the tumour. In Mr. Worthington's case, no valrular disease was found; but one of Mr. Mayo's, like that seen by myself, gave evidence of such disease.

It would, therefore, appear, that extreme slowness of palse, though an occasional attendant on different forms of disease of the heart, is not a necessary feature in any, and, as the peculiar condition of that organ, essential to its production, is probably one of deficient power with the absence of excitement, it may be expected to attend the last stage of diseases which, at an earlier period, are of very different types. Deficiency of power and excitement, existing in a less degree, may be present in those cases in which, for one pulsation in the distant arteries, the heart is found to beat twicea peculiar mode of action described by all writers of diseases of the heart, and of which examples are afforded in the preceding paper by one of the cases related by Mr. Mayo, and by that of Dr. Addison.

It is probable, also, that the same condition may occasionally be found with a powerful cardiac impulse, and strong pulse at the wrist-the heart, as it were, atoning, by one forcible effort, for the more frequerit pulsations which, in a state of health, it should have performed.

Of those cases in which the pulse is found to assume a slow rate without any organic disease being present, and where it is only a temporary peculiarity, either dependant on exhaustion and prostration of strength, or, as occasionally happens, arising without any obvious reason, the imperfect state of our knowledge of the causes of tho hasit'saction protures our furnishing any decided explanation. It is, however, probable, that there may, in these cases, exist a loss of nervous energy in that organ, by which it is rendered less susceptible of the stimulus of the blood, and a deficiency of power and excitement is induced-a state similar to that which, in the former class of cases, results from advanced stages of organic disease.

Royal Infirmary, Edinburgh, April 13, 1842.

\section{ALBUMINOUS URINE.}

TO THE EDITORS OF THE PROVINCIAL MEDICAL JOURNAL.

Gentlemen,-I suspect that albumen exists in the human urine in many cases in which its presence escapes detection.

Inferring from analogy that it would be found in the urine of persons affected with petechice sine febre, although the urine might not contain any of the colouring matter of the blood, I resolved to investigate the matter on the first opportunity. Since last May I have had five cases under my care. In one, the urine was coffee-coloured, and deposited a brown powdery sediment, and coagulated both by heat and upon the addition of nitric acid. In the four other cases the urine appeared natural, and yet, in every one of them, the same tests proved the presence of a large quantity of albumen.

Again, analogy led me to suspect its presence in the urine of females who suddenly wean their infants at a time when they have a full supply of milk. I have since had the opportunity of testing urine under these circumstances in three cases; and in all the quantity of albumen was considerable.

In the petechial disease the urine becomes natural as the patient recovers; and in the cases of weaning, the quantity of albumen gradually diminishes as the milk disappears from the breasts.

\section{I remain, Gentlemen,}

Your obedient servant, Jonas Malden, M.D.

Worcester, April 25, 1842. 